\title{
Light induced grafting-from strategies as powerful tool for surface modification
}

\author{
M. Sangermano*, N. Razza \\ Politecnico di Torino, Dipartimento di Scienza Applicata e Tecnologia, C.so Duca degli Abruzzi 24, 10129 Torino, Italy
}

Received 12 June 2018; accepted in revised form 4 September 2018

\begin{abstract}
Chemical-induced grafting processes can be performed either by a grafting-to method, where preformed polymer chains are grafted on the surface previously activated, or alternatively, the polymer chains can be grown from the surface via a grafting-from method. The last one can be considered a bottom-up approach in which polymers are generated directly on the surface starting from their precursors. As a preliminary process, the substrate is functionalized with specific groups that can initiate a polymerization reaction. Although surface-initiated polymerizations are conventionally induced by a thermal initiator or directly by radicals formed by high energy treatment of the surface, they can be triggered by light. In this regard, light-induced grafting reactions have recently found increasing interest. With this review, by placing emphasis on the initiating system, we aim to show the significant feasibility of photografting-from method to properly functionalize any type of surface.
\end{abstract}

Keywords: molecular engineering, grafting process, photochemistry, surface properties, photoinitiators

\section{Introduction}

Surface modification and functionalization play an important role in many applications with enormous interests both in the academia as well as in industrial sectors [1-3]. Its significance is related to the possibility to control wettability, to improve strength in composite materials, to induced antifouling surface properties or to minimize protein absorption for medical and microfluidic analytical devices.

The surface modification can be either obtained via a physical or a chemical modification. While physical adsorption of polymers on a substrate is the simplest way of surface modification, it leads to modified surfaces which are often thermally unstable, unable to withstand high shear forces, and easily displaceable by chemicals or proteins and cells. On the other hand, chemical modifications give rise to the formation of stable systems characterized by a chemical bond among the surface and the polymer grafted.
Chemically induced grafting processes can be performed either by a grafting-to method (schematized in Figure 1a) where preformed polymer chains are grafted on the surface activated previously. Alternatively, the polymer chains can be grown from the surface via a grafting-from method Schematized in Figure $1 \mathrm{~b}$ ) also known as surface-initiated polymerization.

Among the two different strategies, the graftingfrom methods are preferred since it is possible to achieve higher grafting density and film thickness. In fact, grafting-to methods show limitations due to steric hindrance between polymeric chains, which makes it difficult to tether chain ends at short intermolecular distances.

On the other hand, grafting-from methods can be considered as a bottom-up approach. Indeed, polymers are generated directly on the surface starting from their precursors. As a preliminary process the 


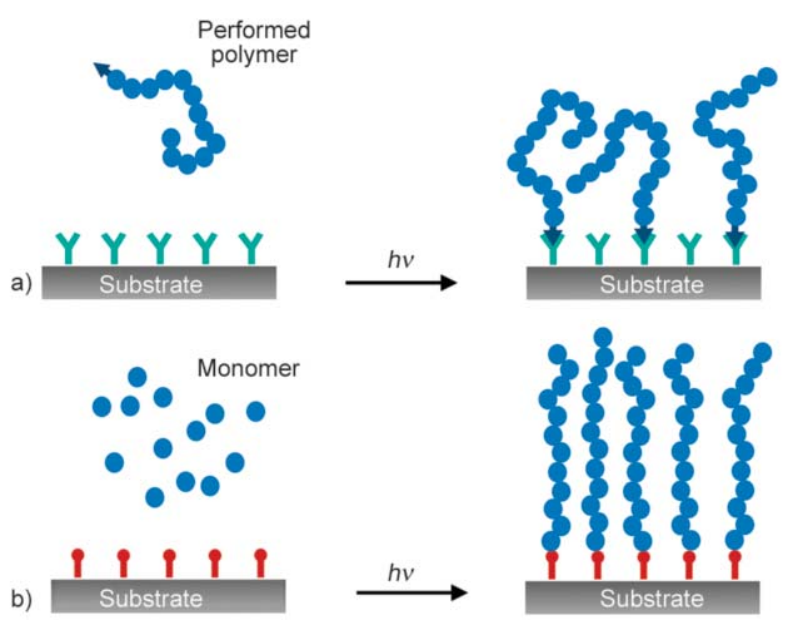

Figure 1.: Scheme of the grafting-to method (a) or graftingfrom (b) method of surface functionalization.

substrate is functionalized with specific groups that are able to initiate a polymerization reaction.

There are many reports in literature related to the surface-initiated polymerization, where a wide variety of polymerization processes are available for the grafting-from approach [4] including, for example, ring-opening polymerization (ROP), ring-opening metathesis polymerization (ROMP) [5] or radical polymerization. The latter may be further tuned by using one of the well-established techniques for controlled polymerization, such as atom transfer radical polymerization (ATRP), [6 ] nitroxide mediated radical polymerization (NMP), [7] or reversible addition-fragmentation chain transfer (RAFT) [8]. Surface-initiated controlled radical polymerization (SI-CRP), allows for precise control over polymer architecture, composition and molecular weight. Because of its versatility and tolerance toward a variety of functional groups it has been widely employed as a synthetic technique to prepare polymer brushes [9]. While the polymerization can be initiated by a thermal initiator or directly by radicals formed by high energy treatment of the surface, light induced triggering of the grafting reaction has recently found increasing interest [10]. The photoinduced method is energy efficient since heat is not required and gives the possibility of a fully spatio-temporal control of the grafting process, allowing an easy access to structured surfaces.

Comprehensive reviews which also included lightinduced grafting-from methods have already been reported [11-15]. Nevertheless, in this review we collect the most recent progress in this field with emphasis on the initiating systems, reporting as well methods for controlled photografting as well as the self-initiating photografting. The aim of this review is to provide the tools to properly conduct photografting modifications by selecting the most suitable initiating system from state-of-the-art scientific contributions.

\section{Photografting initiating systems}

Photografting processes exhibit important advantages with respect to thermal ones, such as: fast reaction rate, low processing cost, easy exploitation of industrialization and the possibility to spatially control the grafted chains.

The pioneering work on grafting polymerization initiated by UV light was published in the 1950s by Oster and Shibata [16] and from different authors in the late 1990s [17, 18].

Generally speaking, photoinduced polymerizations proceed by a chain reaction mechanism involving the propagation of an active center by the interaction with a monomer. The active center can be a radical, a cation or more rarely an anion. The photogenerated active species is the 'true' initiator that is able to initiate the polymerization of a reactive monomer, usually by addition to a multiple bond or by a ring-opening process. Usually it is a radical reactive species. The photoinitiation step of a radical polymerization reaction typically requires the presence of a molecule (photoinitiator), which absorbs the exciting light and leads to radical production. Several types of initiators have been used in the last decade. The photophysical and photochemical processes on which they are founded have been generally well established and mainly divided into two processes: photoscission processes, Figure 2, where an aryl-alkyl ketones produce radical according to a Norrish type I process, ( $\alpha$-cleavage) and hydrogen abstraction, Figure 2, in which a ketyl type radical is generated through photoreduction of the triplet state by hydrogen donors such as tetrahydrofuran (THF), alcohols or amines.

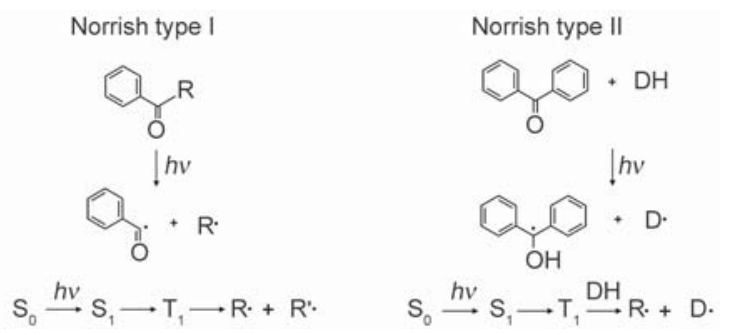

Figure 2. scheme of the different mechanism of action of the radical photoinitiator: Norrish Type I (Figure 1a) and Norrish Type II (Figure 1b). 


\subsection{Norrish type II initiating systems}

When using the photografting process the most used photoinitiator in order to generate radicals on the substrate surface have been the Norrish type II photoinitiator benzophenone (BP) $[19,20]$.

In principle, when UV irradiated, BP or BP-based molecules are excited to a singlet state and then jump to a triplet state by intersystem crossing (ISC; see Figure 3). Several studies have demonstrated that BP and its derivatives in a triplet state undergo hydrogen-abstracting reactions from substrates, consequently providing surface radicals $(\mathrm{R} \bullet)$ capable of initiating surface graft polymerization. The resulting benzopinacol radicals $(\mathrm{BP}-\mathrm{OH} \bullet$ ) are relatively less reactive and not prone to promote free radical polymerization, but tend to participate in termination by coupling reaction.

Different substrates have been treated with BP in a first step, and subsequently photoactivated in order to promote radical chain-grow polymerization on the surface.

Some authors photografted polyacrylamide onto cotton fabrics by linking photo-active moiety benzophenone chromophoric groups. As a result, the grafting was successfully achieved, and the grafting rate increased with increasing benzophenone concentration and photo-irradiation (grafting) time. The as-grafted cotton fabrics showed significantly increased thermal stability, and also through a simple chlorination process, it obtained excellent antibacterial ability [21]. Ma et al. [22] proposed a two-step process to photografting polypropylene membranes: in the first

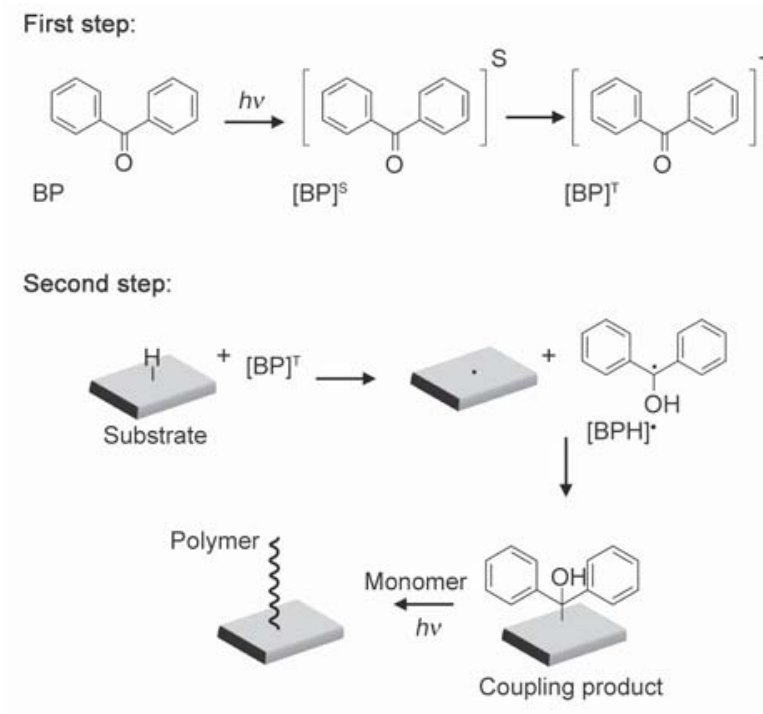

Figure 3. Schematization of benzophenone grafting-from mechanism. step irradiated BP is able to abstract hydrogen from PP substrate, the photogenerated radicals on the surface quickly combine with semipinacol radicals. In the second step, the monomer solution is added to the active substrate and the surface initiators initiate the graft polymerization under UV irradiation.

Roppolo et al. [23] followed a similar concept to photografting graphene oxide (GO) surface. The process is schematized in Figure 4. As previously discussed, by dispersing GO in the presence of BP, under irradiation the semipinacol radical are able to recombine with remaining radicals on the GO sheets creating a covalent bond. In the second step, during UV-irradiation, a homolytical break the bond between the semipinacol group and the GO surface is induced, generating an initiating point on the GO surface, so a radical chain grown polymerization is promoted in the presence of a suitable monomer.

Luan et al. [24] modified the surface of biomedical elastomers poly(styrene- $b$-(ethylene-co-butylene)$b$-styrene) (SEBS). Oxygen plasma process was used as pre-treatment in order to form polar onto the surface of SEBS film. This treatment improved the wetting properties of both hydrophilic NVP monomer and ethanol solution of BP initiator on the plasmatreated substrate, thus facilitating the uniform distribution of grafted chains on the surface. In the UV-induced graft polymerization process, SEBS films in BP solution were exposed to UV irradiation which caused BP initiator abstracted hydrogen from the SEBS backbones to form surface free radicals, and further initiated the surface graft polymerization of $N$-vinyl pyrrolidone (NVP) monomer. After the surface photografting with NVP, the water contact angle decreased to about $40^{\circ}$ and protein adsorption and platelet adhesion were significantly inhibited.

Sugiura et al. [25] reported that the surface of polydimethylsiloxane (PDMS) can be micropatterned with poly(ethylene glycol) (PEGDA) in one step photografting process by using a reaction mixture of monomer and BP. The PEGDA-modified PDMS surface exhibited stable hydrophilicity after more than two months storage in air. Additional, the micropatterned surface showed the ability to generate micropatterned protein adsorption and cell adhesion thanks the poly(ethylene glycol) which has low protein adsorption and low cell attachment.

Schneider et al. [26] accurately investigated the process parameters for the photografting of the inner channel of polydimethylsiloxane microfluidic 


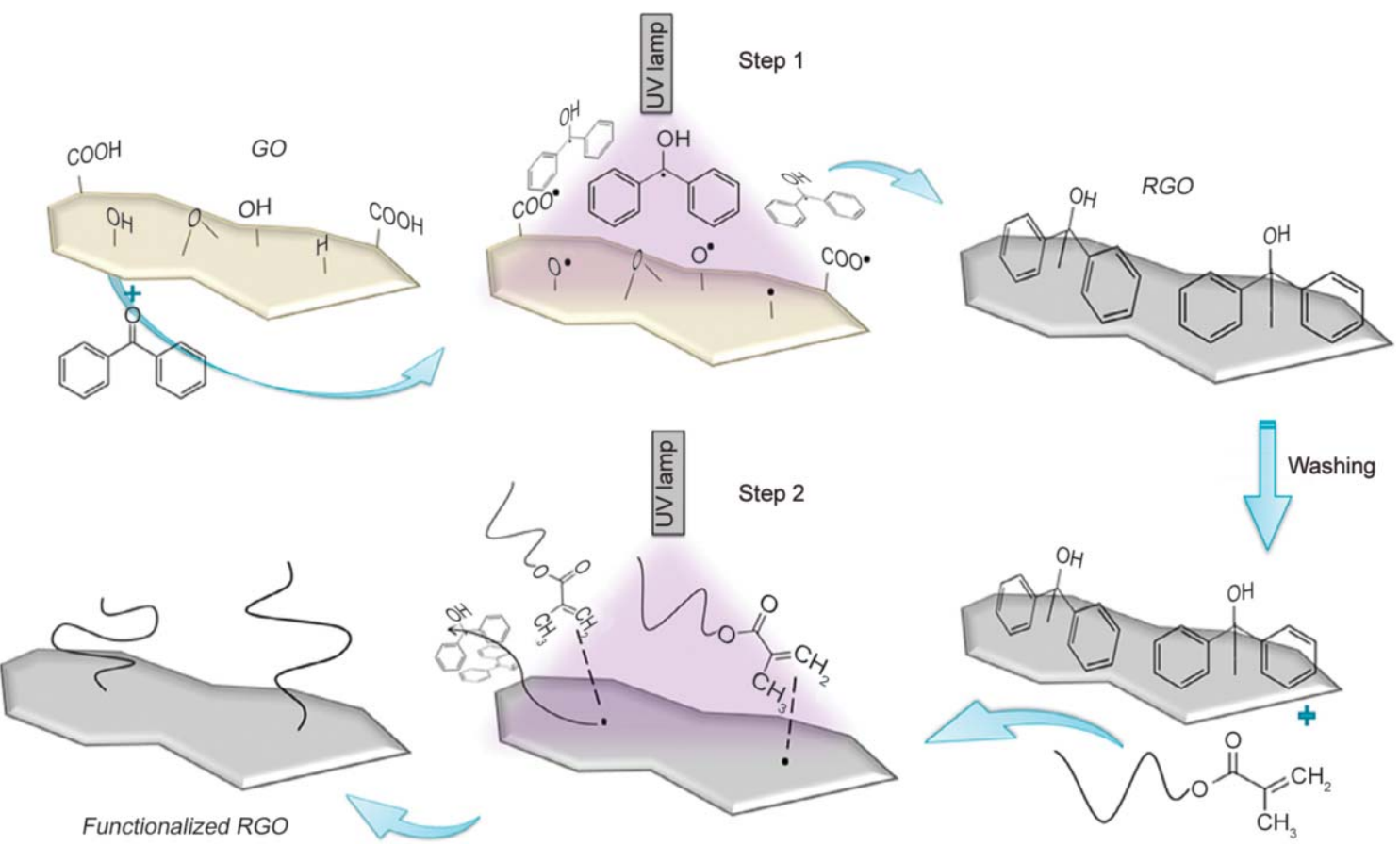

Figure 4. Schematic representation of the two-step photografting process of graphene oxide surface. Reproduced from ref. [23].

devices with poly(acrylic acid), PPA, even for very complex geometry. A solution of BP in acetone when applied inside the microfluidic channels diffuses into the PDMS matrix. After washing, the channels filled with acrylic acid (PA) can beexposed to UV-light to generate the photografted PPA surface.

Benzophenone as photoinitiator has also been employed in PDMS materials to photograft methacrylate monomer bearing a phosphorylcholine moiety prior photogeneration of semipinacols. It was shown that it is possible to tailor protein repellency and lubrication property by playing on the grafting density [27].

Feng et al. [28] anchored BP molecules onto polycarbonateurethane surfaces and, by using UV-light, induced the polymerization of poly(ethylene glycol) monomers with different molecular weight to improve haemocompatibility and increment hydrophilicity. They showed that monomer molecular weight affects platelet adsorption and haemocompatibility, which might be explained with an optimum balance between poly(ethylene glycol) grafting density and chain length.

It has also been recently shown that benzophenone can be used for the surface modification of cellulose with poly(ethylene glycol). Morphological analysis showed that poly(ethylene glycol) surfaces assemble in very sharp formation of very sharp nanometric architectures on the surface of cellulose [29].

Benzophenone has also been adopted in the synthesis of Janus particles (i.e. particles with topologically

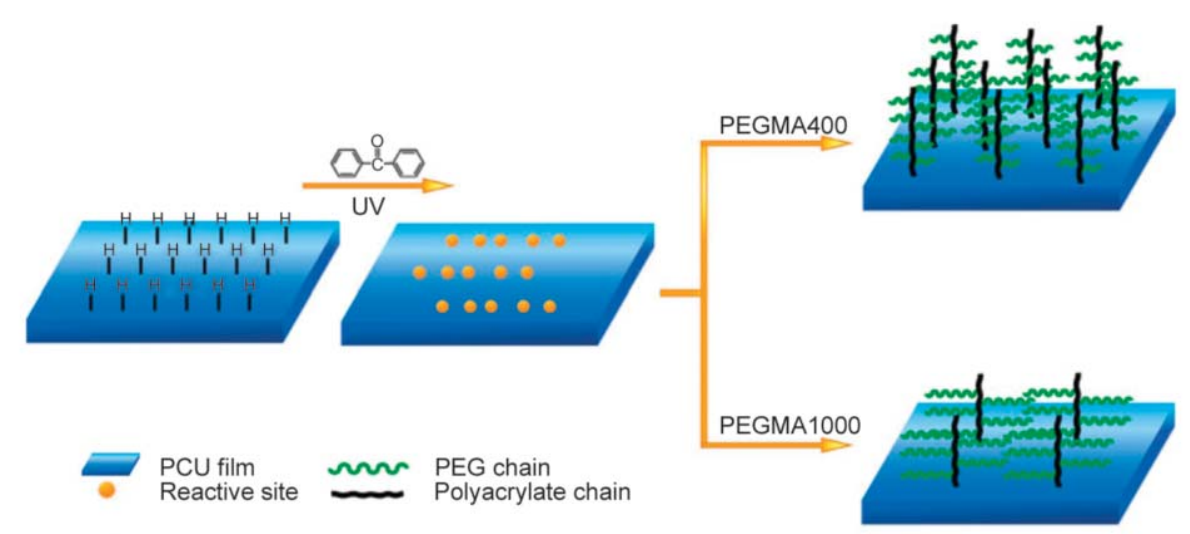

Figure 5. Schematic illustration of poly(ethylene glycol) photografting-from polycarbonateurethane films. Reproduced from ref. [28]. 


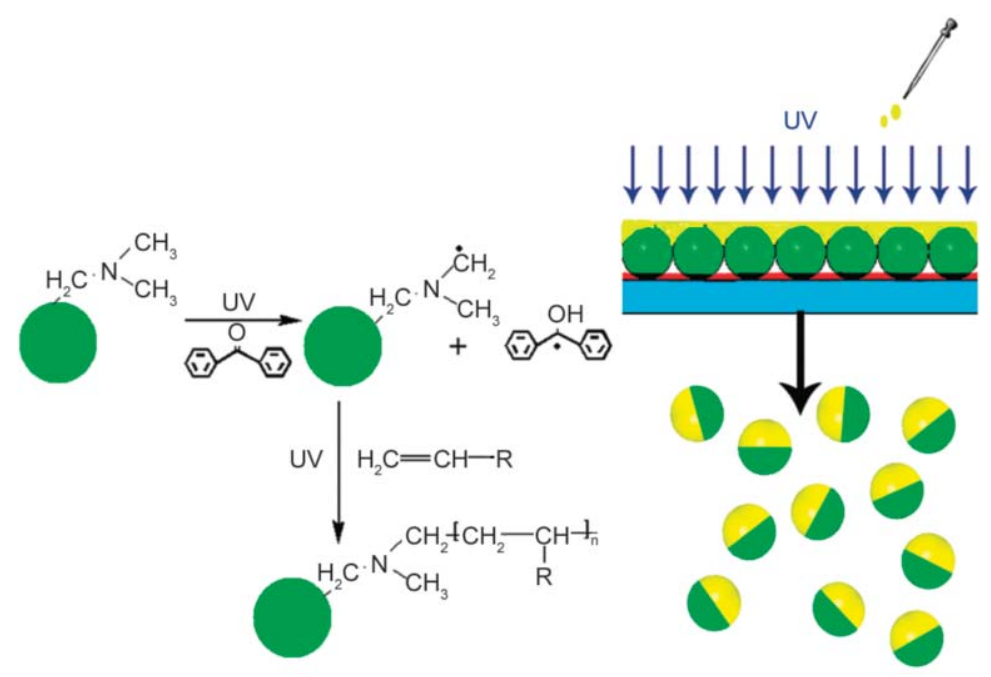

Figure 6. Preparation of Janus particles by the selective photografting of poly(styrene) particles with tertiary amine groups on surfaces by using benzophenone as photoinitiator. Reproduced from ref. [30].

distinct domains with different chemistry) via selective photografting. In their study, poly(styrene) polymeric particles with tertiary amine groups on surfaces were immobilized on a planar substrate and treated with BP (Figure 6). Subsequently, the particles surface exposed to UV-light was photografted with poly (methacrylate) leading to the formation of particles with compartmentalized surfaces [30].

The applicability of BP photoinitiator is generally limited by the fact that the surface generation of semipinacols requires the abstraction of hydrogen and therefore this limits its use to surfaces which possess hydrogens to be abstracted. Gam-Derouich et al. [31] were able to extend the use of BP to metal surfaces by using a BP-derivative diazonium salt. Indeed, as illustrated in Figure 7, photoinitiator was immobilized on a gold surface via electrochemical reduction. The immobilized photoinitiator, in along with dimethylaniline as a co-initiator, showed to be effective in the photografting of different polymer such as poly(styrene), poly(methyl methacrylate), and poly(2-hydroxyethyl methacrylate).

\subsection{Norrish type I initiator}

Derivatives of the widely used 2,2-azobis-(isobutyronitrile) (AIBN) initiator have been also adapted in surface modification via light-induced grafting-from $[32,33]$. However, these azo initiators show a relatively low absorbency and long half-life [34] and consequently, long curing times are needed. Additionally, the photoactivation of AIBN derivatives produces two radicals with the same reactivity, only one of which is tethered to the surface. The unanchored radical diffuses into solution and initiates polymerization in the

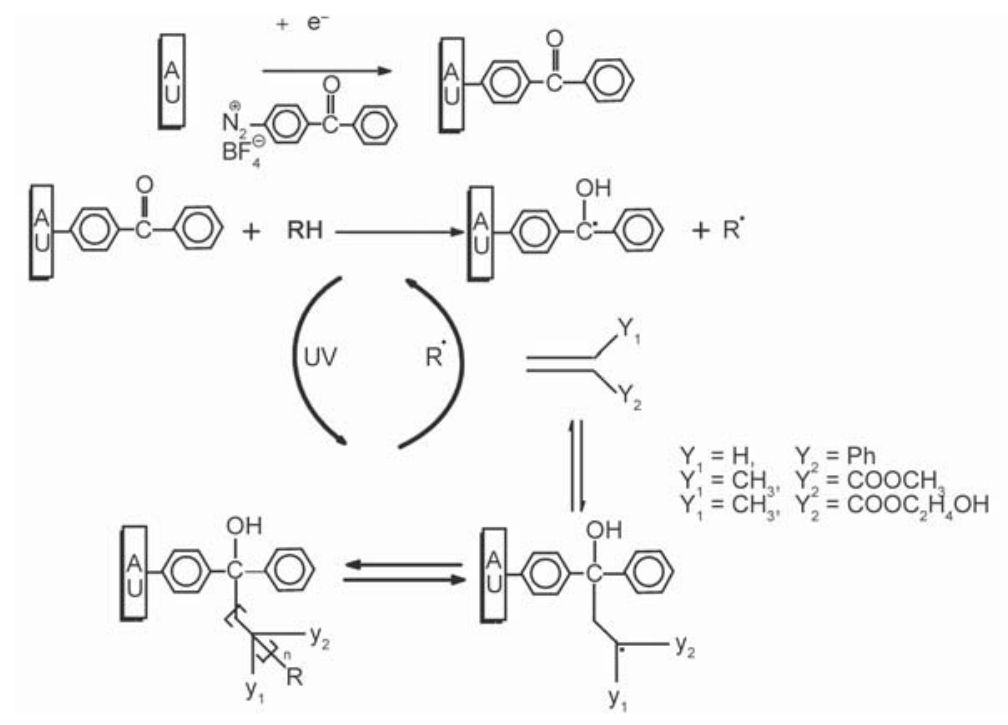

Figure 7. Immobilization of benzoylphenyl photoinitiators on a gold surface via electrochemical and graft photopolymerized monomers using dimethylaniline as a co-initiator (H donor). Reproduced from ref. [31]. 
bulk. The so produced bulk polymer intercalates into the grafted brush and requires a time-demanding purification for complete removal.

More recently Wang et al. [35] proposed the synthesis of alkoxy-functionalized bis-(acylphosphane) oxides (BAPO) via a stable bis(mesitoyl)phosphane intermediate. The functionalized BAPO was attached on the nanocellulose particles and poly(methyl methacrylate) chains were grown by the light-triggered grafting onto the surface. In another work from the same group, a tri(methoxy)silyl-substituted BAPO derivative was attached on the cotton surface and fluorinated acrylates were photografting onto cotton fabrics [36].

Alkoxy functionalized BAPO was also proposed for the glass surface modification, obtaining a photoactive surface. By spreading the monomer on the functionalized substrate and by UV irradiation in the presence of either a partially fluorinated acrylate or a specifically synthesized polysiloxane containing polymerizable acrylate functions allowed the generation of polymer chains which grew from the surface in an efficient radical polymerization process (' $\mathrm{graft}$ ing-from' procedure). Durable hydrophobic surfaces were prepared characterized by contact angles between 93 and $95^{\circ}$ [37].

The same surface-anchored bis(acyl)phosphane oxide photoinitiator was used to fabricate silica nanoparticles homogeneously covered with poly(ethylene glycol) polymer chains or with chains of two different polymers (poly(ethylene glycol) and poly(lauryl methacrylate)) segregated in distinct domains. The authors showed how photografting strategies can be employed for the fabrication of very small Janus nanoparticles by photopatterning the surface of each single particle. The Janus-like photografting was achieved by initiating the polymerization of the hydrophilic monomer only on the free-surface of immobilized nanoparticles. In a second step, the unreacted photoinitiator functionalities were used for the photografting of the lipophilic monomer [38].

Yin and coworkers proposed another strategy involving surface-anchored dendric thioxanthone (TX) photoinitiators. In this approach (Figure 8), in the presence of amino groups as co-initiators, light-irradiation leads to the formation of a ketyl radical from the thioxanthone and another radical coming from the hydrogen donor amine. In the presence of a suitable monomer, the polymerization is initiated by the amino radicals while the ketyl radical are generally very less reactive because of the steric hindrance. This approach has been adopted on both planar surfaces [39] to grow poly $(N$-isopropylacrylamide) brushes and on microparticle surfaces [40] to grow poly(methyl methacrylate) brushes.

Another strategy to photograft polymers on different substrate is to anchor on the surface thiol groups, by a simply silanization of the surface with alkoxy-functionalized thiol. Under UV-light thiyl radicals are generated from the thiol groups and these radicals are able to initiate free-radical chain growth polymerization form the surface. This approach has been used by Mostegel and colleagues to photopattern planar surfaces with polyethylene (glycol) brushes and biomolecules. When thiol functionalities are exposed to UV-light in presence of oxygen, UV-induced photooxidation of the thiol occurs which yields to sulfonate groups. These sulfonic acid groups were used for immobilization of amino-functionalized biomolecules while the intact thiol groups were used to induce a photografting polymerization of polyethylene (glycol) [41]. Razza et al. [42] employed a similar strategy to fabricate Janus particles from micrometric thiol-functionalized silica particles. A photograftingfrom polymerization was initiated from thiol-functionalized silica particles partially masked in colloidosomes structures. The photogenerated thiyl radicals initiated the photografting of poly(ethylene glycol) brushes, while the unreacted thiol groups were employed to bind photogenerated gold nanoparticles.

The group of Bowman reported the use of thiol surface functionalities to photoactivate the formation of PEG-brushes. The photogenerated thiyl radical adds across the carbon-carbon bond of the m-PEGMA to form a carbon-sulfur bond and carbon radical. The just formed carbon radical can add to another m-PEGMA molecule and propagate leading to the formation of

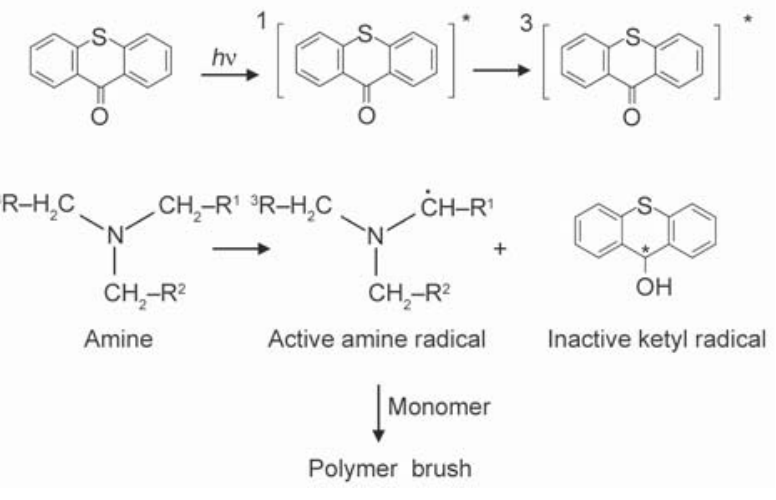

Figure 8. Structure of hyper branched TX and initiation mechanism. Reproduced and adapted from ref. [40]. 
PEG-brushes [43-45]. Also some ketones and aldehydes were reported to undergo hydrogen abstraction from substrate upon UV-irradiation. So, in a very similar way as in the case of BP these compounds could be used to promote photografting-from process, where the monomer is added on the radical generated on the surface [46].

\section{Control photografting}

Living photografting polymerization was reported for the first time by Yang and Ránby [47] that found the possibility to control the radical chain grown polymerization allowing to control the length, composition, and the distribution of the grafted chains on the surfaces. The suggested strategy occurs in two steps: in the first step dormant end groups are covalently attach on the surface of the substrate by photografting monomer solutions containing BP, which introduces graft chains end-capped with semibenzopinacol groups. In the second step living radical graft polymerization of monomers is performing by re-activating the dormant end groups. The above procedure is schematized in Figure 9.

Bowman et al. [48] investigated the effect of the principal factor affecting sequential photoinduced grafting polymerization. It was found that the graft polymerization rate of acrylic acid increases linearly with increasing surface initiator concentration, and the formation rate of the surface initiator follows a decreasing order dependent on solvent: benzene $>$ chloroform $>$ hexane $>$ methanol $>$ cyclohexane $>$ dimethyl sulfoxide.

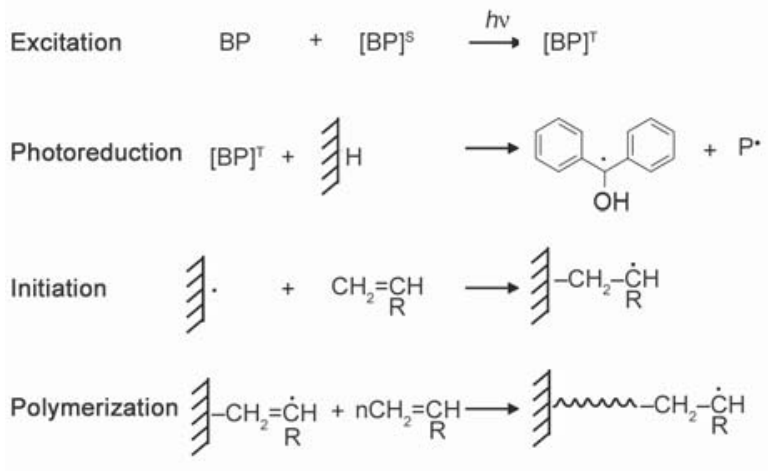

Benetti et al. [49], as well as Tazaki and Otsu [50] reported the use of 'photo-iniferters' (initiator, transfer agent, and terminator) chemical bonded on the substrate. Under irradiation the 'photo-iniferters' yields a pair of radicals: the reactive one can initiate monomers to produce a polymer end radical; the less reactive one cannot initiate the polymerization of monomers, but prefers to terminate the growing polymer chains, forming dithiocarbamyl end-capped chain which can be dissociated again to form a radical pair by UV radiation, generating a living/ control polymerization.

Heeb et al. [51] reported the fabrication of a thin layer of poly(methacrylic acid) on silicon substrates by controlled photografting strategy. A photoiniferter with a silane functionality, $\mathrm{N}-\mathrm{N}$-(diethylamino) dithiocarbamates (trimethoxy) silane, was immobilized on the surface via conventional condensation reactions with surface silanols. After photografting, no special washing was required because the homopolymerization of the monomer was completely suppressed by using LEDs light source (cold light to avoid unwanted thermal polymerizations) with a proper wavelength (selected in the region where the monomer does not absorb) [51]. By using the same photo-iniferter, Spencer's group showed how thin films of poly(acrylamide) (PAAm) brushes can be grown from iniferter-functionalized silicon substrates by UVLEDinitiated photopolymerization. The adopted photografting strategy allowed the controlled fabrication of very thick films (up to $1 \mu \mathrm{m}$ ) in an aqueous environment. This was carried out over a period of less
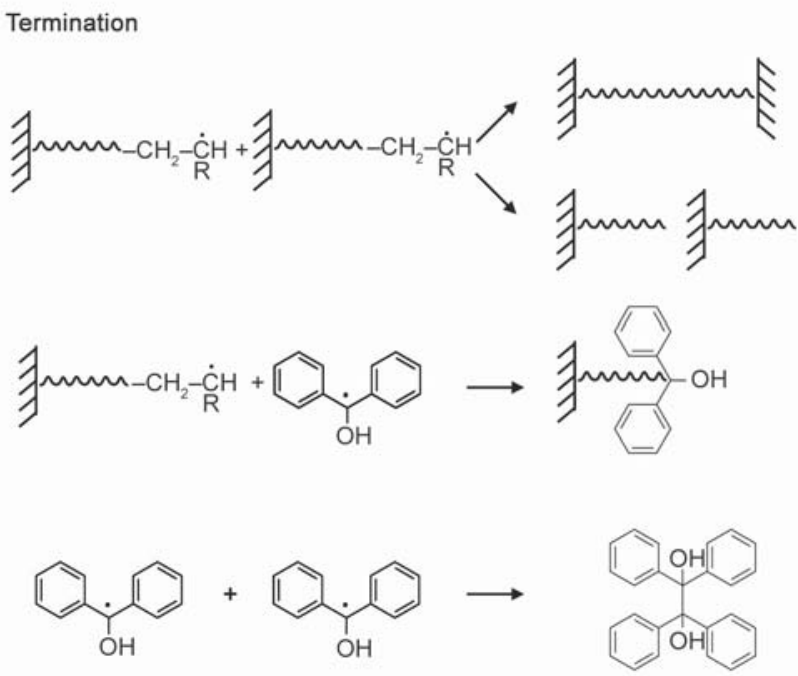

Figure 9. Scheme of the proposed living-control photografting-from method. Reproduced and adapted from ref. [47]. 
than $1 \mathrm{~h}$ of polymerization and in the absence of side reactions [52].

\section{Self-initiating photografting}

There are some monomers, such as Maleic anhydride (MAH) which can undergo in a photografting polymerization even in the absence of any photoinitiator. In fact, under UV-irradiation, MAH molecules produce excimers that are able to abstract hydrogen from the backbones of the substrate and form surface free radicals which could consequently initiate graft polymerization and homopolymerization of MAH as well as other monomers [53]. With LDPE as the substrate and after UV irradiation, the conversion percentage and grafting efficiency of MAH can reach nearly 80 and $70 \%$, respectively.

Another important example of self-initiated photografting is shown when poly(ether sulfone) ultrafiltration membrane are irradiated in the presence of $\mathrm{N}$-vinyl-2-pyrrolidinone. The resulting grafted membrane showed a severe loss of protein rejection [54]. The grafting-from method is activated due to the use of very low wavelength, where the polymer absorbing generating free-radicals on its surface [55].

Jordan and coworkers $[56,57]$ reported in several work the photogeneration of polymer brushes by direct self-initiated photografting. This occurs by hydrogen abstraction by a radical mechanism under the UV-illumination via from glassy carbon and silicon carbide [58] substrates. They demonstrated that the presence of $\mathrm{C}-\mathrm{OH}$ functionalities onto the surface is a crucial parameter for the hydrogen abstraction.

Similarly, Steenackers et al. [59] demonstrated that uniform of patterned polymer brushed can be grown from graphene without the use of any initiator and by simply UV-irradiation. They proved that photopolymerization occurs at existing defect sites. Polymerizations were performed with a wide range of monomers (including styrene, methyl methacrylate (MMA), $\mathrm{N}, \mathrm{N}$-dimethylaminoethyl methacrylate (MAEMA), methacrylatoethyl trimethyl ammonium chloride (METAC), and 4-vinyl pyridine). Additionally, they demonstrated there is non-detectable disruption of the basal plane conjugation of graphene after the photografting.

Shiojima and colleagues reported a highly efficient methodology for preparing a poly(2-methacryloyloxyethyl phosphorylcholine) layer on the surface of poly(ether ether ketone) (PEEK) by photoinduced and self-initiated graft polymerization. PEEK has diphenylketone unit in the main chain which is similar to the structure of benzophenone. Therefore, when photoirradiated, activation of diphenylketone units in the PEEK chain is induced and semibenzopinacol radicals are formed. These radicals can initiate polymerization of surrounding monomers at the PEEK interface. In the study, the effects of inorganic salt addition ( $\mathrm{LiCl}, \mathrm{NaCl}$ and $\mathrm{KCl}$ ) was evaluated in terms of increase in polymerization rate. These findings can be explained considering the ionic hydration of the 2-methacryloyloxyethyl phosphorylcholine monomer which is translated in a monomer concentrating effect [60].

A mussel-inspired photografting on colloidal spheres was reported from Jia's lab. Monodispersed $\mathrm{SiO}_{2}$ spheres with an average diameter of $220 \mathrm{~nm}$ were coated with a thin layer of polydomapmine. They demonstrated that surface-initiated polymerization reactions can be carried out on polydopamine (PDA)coated surfaces via a simple surface modification approach. Based on a photopolymerization without adding any photoinitiator or any photosensitizer. In their study, thermally-responsive poly(2-(dimethylamino) ethyl methacrylate) polymer were grown from the polydopamine layer [61]. The same group, in a similar approach, reported the fabrication of self-induced photografting after depositing a thin layer of green tea polyphenols (TP). Indeed, the UVirradiated generates on the TP surface, surface-bound radicals which can be used for a photoinduced polymerization. When compared with polydopaminecoated surfaces, green tea polyphenol layers were typically colorless instead of dark-black which can be a plus in some applications [62].

\section{Conclusions}

In this review, we have shown the important feasibility of photografting-from methods to properly functionalize any type of surface. We have discussed the photoactivated grafting-from process either using a photoinitiator, able to abstract hydrogen form the surface, or by using functionalized photoinitiators anchored on different substrate and ready to photoactive radical chain grown polymerization. Attention has been devoted to the controlled photografting methods which allow to control length, composition, and the distribution of the grafted chains on the surfaces.

This review aims to stress the importance of the photografting-from methods to control the surface of different substrates, achieving a critical view of 
the most important contribution in this field to have the tools to properly use the photografting reaction.

\section{References}

[1] Stamm M.: Polymer surfaces and interfaces: Characterization, modification and applications. Springer, Berlin (2008).

[2] Chen W. L., Cordero R., Tran H., Ober C.K.: 50 ${ }^{\text {th }}$ anniversary perspective: polymer brushes: novel surfaces for future materials. Macromolecules, 50, 4089-4113 (2017).

https://pubs.acs.org/doi/abs/10.1021/acs.macromol.7b00450

[3] Ruckenstein E., Li Z.: Surface modification and functionalization through the self-assembled monolayer and graft polymerization. Advances in Colloid and Interface Science, 113, 43-63 (2015).

https://doi.org/10.1016/j.cis.2004.07.009

[4] Olivier A., Meyer F., Raquez J-M., Damman P., Dubois P.: Surface-initiated controlled polymerization as a convenient method for designing functional polymer brushes: From self-assembled monolayers to patterned surfaces. Progress in Polymer Science, 37, 157-181 (2012). https://doi.org/10.1016/j.progpolymsci.2011.06.002

[5] Yavuz M. S., Jensen G. C., Penaloza D. P., Seery T. A., Pendergraph S. A., Rusling J., Sotzing G. A.: Gold nanoparticles with externally controlled, reversible shifts of local surface plasmon resonance bands. Langmuir, 25, 13120-13124 (2009). https://doi.org/10.1021/la901779k

[6] Fristrup C. J., Jankova K., Hvilsted S.: Surface-initiated atom transfer radical polymerization - A technique to develop biofunctional coatings. Soft Matter, 5, 4623 4634 (2009).

https://pubs.rsc.org/doi/10.1039/B821815C

[7] Voccia S., Bech L., Gilbert B., Jérôme R., Jérôme C.: Preparation of poly( $\varepsilon$-caprolactone) brushes at the surface of conducting substrates. Langmuir, 20, 10670 10678 (2004). https://doi.org/10.1021/la048357u

[8] Raula J., Shan J., Nuopponen M., Niskanen A., Jiang H., Kauppinen E. I., Tenhu H.: Synthesis of gold nanoparticles grafted with a thermoresponsive polymer by surface-induced reversible-addition-fragmentation chaintransfer polymerization. Langmuir, 19, 3499-3504 (2003).

https://pubs.acs.org/doi/10.1021/la026872r

[9] Zoppe J. O., Ataman N. C., Mocny P., Wang J., Moraes J., Klok H-A.: Surface-initiated controlled radical polymerization: State-of-the-art, opportunities, and challenges in surface and interface engineering with polymer brushes. Chemical Reviews, 117, 1105-1318 (2017). https://pubs.acs.org/doi/10.1021/acs.chemrev.6b00314

[10] Chen M., Zhong M., Johnson J. A.: Light-controlled radical polymerization: Mechanisms, methods, and applications. Chemical Reviews, 116, 10167-10211 (2016). https://pubs.acs.org/doi/abs/10.1021/acs.chemrev.5b00671
[11] Yagci Y., Jockusch S., Turro N. J.: Photoinitiated polymerization: Advances, challenges, and opportunities. Macromolecules, 43, 6245-6260 (2010). https://pubs.acs.org/doi/10.1021/ma1007545

[12] Deng J., Wang L., Liu L., Yang W.: Developments and new applications of UV-induced surface graft polymerizations. Progress in Polymer Science, 34, 156-193 (2009).

https://doi.org/10.1016/j.progpolymsci.2008.06.002

[13] Bhattacharya A., Misra B. N.: Grafting: A versatile means to modify polymers: Techniques, factors and applications. Progress in Polymer Science, 29, 767-814 (2004).

https://doi.org/10.1016/j.progpolymsci.2004.05.002

[14] Kato K., Uchida E., Kang E-T., Uyama Y., Ikada Y.: Polymer surface with graft chains. Progress in Polymer Science, 28, 209-259 (2003). https://doi.org/10.1016/S0079-6700(02)00032-1

[15] Goddard J. M., Hotchkiss J. H.: Polymer surface modification for the attachment of bioactive compounds. Progress in Polymer Science, 32, 698-725 (2007). https://doi.org/10.1016/j.progpolymsci.2007.04.002

[16] Oster G., Shibata O.: Graft copolymer of polyacrylamide and natural rubber produced by means of ultraviolet light. Journal of Polymer Science, 26, 233-234 (1957). https://doi.org/10.1002/pol.1957.1202611311

[17] Rånby B.: Photochemical modification of polymers Photocrosslinking, surface photografting, and lamination. Polymer Engineering and Science, 38, 1229-1243 (1998). https://doi.org/10.1002/pen.10292

[18] Rånby B.: Surface modification and lamination of polymers by photografting. International Journal of Adhesion and Adhesives, 19, 337-343 (1999). https://doi.org/10.1016/S0143-7496(98)00066-9

[19] Cho J-D., Kim S-G., Hong J-W.: Surface modification of polypropylene sheets by UV-radiation grafting polymerization. Journal of Applied Polymer Science, 99, 1446-1461 (2006). https://doi.org/10.1002/app.22631

[20] Pan B., Viswanathan K., Hoyle C. E., Moore R. B.: Photoinitiated grafting of maleic anhydride onto polypropylene. Journal of Polymer Science Part A: Polymer Chemistry, 42, 1953-1962 (2004). https://doi.org/10.1002/pola.20038

[21] Hong K. H., Liu N., Sun G.: UV-induced graft polymerization of acrylamide on cellulose by using immobilized benzophenone as a photo-initiator. European Polymer Journal, 45, 2443-2449 (2009). https://doi.org/10.1016/j.eurpolymj.2009.04.026

[22] Ma H., Davis R. H., Bowman C. N.: A novel sequential photoinduced living graft polymerization. Macromolecules, 33, 331-335 (1999). https://doi.org/10.1021/ma990821s 
[23] Roppolo I., Chiappone A., Bejtka K., Celasco E., Chiodoni A., Giorgis F., Sangermano M., Porro S.: A powerful tool for graphene functionalization: Benzophenone mediated UV-grafting. Carbon, 77, 226-235 (2014).

https://doi.org/10.1016/j.carbon.2014.05.025

[24] Luan S., Zhao J., Yang H., Shi H., Jin J., Li X., Liu J., Wang J., Yin J., Stagnaro P.: Surface modification of poly(styrene- $b$-(ethylene-co-butylene)- $b$-styrene) elastomer via UV-induced graft polymerization of $N$-vinyl pyrrolidone. Colloids and Surfaces B: Biointerfaces, 93, 127-134 (2012).

https://doi.org/10.1016/j.colsurfb.2011.12.027

[25] Sugiura S., Edahiro J-I., Sumaru K., Kanamori T.: Surface modification of polydimethylsiloxane with photografted poly(ethylene glycol) for micropatterned protein adsorption and cell adhesion. Colloids and Surfaces B: Biointerfaces, 63, 301-305 (2008).

https://doi.org/10.1016/j.colsurfb.2007.12.013

[26] Schneider M. H., Willaime H., Tran Y., Rezgui F., Tabeling P.: Wettability patterning by UV-initiated graft polymerization of poly(acrylic acid) in closed microfluidic systems of complex geometry. Analytical Chemistry, 82, 8848-8855 (2010).

https://doi.org/10.1021/ac101345m

[27] Goda T., Matsuno R., Konno T., Takai M., Ishihara K.: Photografting of 2-methacryloyloxyethyl phosphorylcholine from polydimethylsiloxane: Tunable protein repellency and lubrication property. Colloids and Surfaces B: Biointerfaces, 63, 64-72 (2008).

https://doi.org/10.1016/j.colsurfb.2007.11.014

[28] Feng Y., Zhao H., Behl M., Lendlein A., Guo J., Yang D.: Grafting of poly(ethylene glycol) monoacrylates on polycarbonateurethane by UV initiated polymerization for improving hemocompatibility. Journal of Materials Science: Materials in Medicine, 24, 61-70 (2013). https://ink.springer.com/article/10.1007/s10856-012-4685-4

[29] Lavagna L., Nisticò R., Chiappone A., Pavese M.: Facile photo-induced growth of polymeric nanostructures onto cellulose: The poly(ethylene glycol) methacrylate (PEGMA)@cellulose case study. Materials Letters, 227, 202-204 (2018).

https://doi.org/10.1016/j.matlet.2018.05.074

[30] Liu L., Ren M., Yang W.: Preparation of polymeric Janus particles by directional UV-induced reactions. Langmuir, 25, 11048-11053 (2009).

https://pubs.acs.org/doi/10.1021/1a901364a

[31] Gam-Derouich S., Carbonnier B., Turmine M., Lang P., Jouini M., Ben Hassen-Chehimi D., Chehimi M.: Electrografted aryl diazonium initiators for surface-confined photopolymerization: A new approach to designing functional polymer coatings. Langmuir, 26, 1183011840 (2010).

https://doi.org/10.1021/la100880j

[32] Schmidt R., Zhao T., Green J-B., Dyer D. J.: Photoinitiated polymerization of styrene from self-assembled monolayers on gold. Langmuir, 18, 1281-1287 (2002). https://doi.org/10.1021/la011445j
[33] Fan X., Xia C., Fulghum T., Park M-K., Locklin J., Advincula R. C.: Polymer brushes grafted from clay nanoparticles adsorbed on a planar substrate by free radical surface-initiated polymerization. Langmuir, 19, 916923 (2003).

https://cdn-pubs.acs.org/doi/10.1021/1a026039u

[34] Vernekar S. P., Ghatge N. D., Wadgaoknar P. P.: Decomposition rate studies of azobisnitriles containing functional groups. Journal of Polymer Science Part A: Polymer Chemistry, 26, 953-958 (1998).

https://doi.org/10.1002/pola.1988.080260321

[35] Wang J., Siqueira G., Müller G., Rentsch D., Huch A., Tingaut P., Levalois-Grützmacher J., Grützmacher H.: Synthesis of new bis(acyl)phosphane oxide photoinitiators for the surface functionalization of cellulose nanocrystals. Chemical Communications, 52, 28232826 (2006).

https://pubs.rsc.org/en/content/articlelanding/2016/cc/c5cc $\underline{09760 f}$

[36] Huber A., Kuschel A., Ott T., Santiso-Quinones G., Stein D., Bräuer J., Kissner R., Krumeich F., Schönberg H., Levalois-Grützmacher J., Grützmacher H.: Phosphorous-functionalized bis(acyl)phosphane oxides for surface modification. Angewante Chemie, 124, 4726-4730 (2012).

https://doi.org/10.1002/ange.201201026

[37] Sangermano M., Periolatto M., Castellino M., Wang J., Dietliker K., Grützmacher J. L., Grützmacher H.: A simple preparation of photoactive glass surfaces allowing coatings via the 'grafting-from' method. ACS Applied Materials and Interfaces, 8, 19764-19771 (2016). https://pubs.acs.org/doi/10.1021/acsami.6b05822

[38] Razza N., Rizza G., Coulon P-E., Didier L., Fadda G., Voit B., Synytska A., Grützmacher H., Sangermano M.: Enabling the synthesis of homogeneous or Janus hairy nanoparticles through surface photoactivation. Nanoscale, 10, 14492-14498 (2018).

https://pubs.rsc.org/en/content/articlelanding/2018/nr/c8nr $04239 \mathrm{j}$

[39] Jia X., Jiang X., Liu R., Yin J.: Poly( $N$-isopropylacrylamide) brush fabricated by surface-initiated photopolymerization and its response to temperature. Macromolecular Chemistry and Physics, 210, 1876-1882 (2009). https://doi.org/10.1002/macp.200900291

[40] Chen F., Jiang X., Liu R., Yin J.: Well-defined PMMA brush on silica particles fabricated by surface-initiated photopolymerization (SIPP). ACS Applied Materials and Interfaces, 2, 1031-1037 (2010).

https://doi.org/10.1021/am900758j

[41] Mostegel F. H., Ducker R. E., Rieger P. H., El Zubir O., Xia S., Radl S. V., Edler M., Cartron M. L., Hunter C. N., Leggett G. J. Griesser T.: Versatile thiol-based reactions for micrometer- and nanometer-scale photopatterning of polymers and biomolecules. Journal of Materials Chemistry B, 3, 4431-4438 (2015). https://pubs.rsc.org/en/content/articlelanding/2015/tb/c5tb $\underline{00345 h}$ 
[42] Razza N., Castellino M., Sangermano M.: Fabrication of janus particles via a 'photografting-from' method and gold photoreduction. Journal of Materials Science, 52, 13444-13454 (2017).

https://ink.springer.com/article/10.1007/s10853-017-1459-x

[43] Kilambi H., Reddy S. K., Schneidewind L., Lee T. Y., Stansbury J. W., Bowman C. N.: Design, development, and evaluation of monovinyl acrylates characterized by secondary functionalities as reactive diluents to diacrylates. Macromolecules, 40, 6112-6118 (2007).

https://doi.org/10.1021/ma062708p

[44] Wei H., Li Q., Ojelade M., Madbouly S., Otaigbe J. U., Hoyle C. E.: Thiol-ene free-radical and vinyl ether cationic hybrid photopolymerization. Macromolecules, 40, 8788-8793 (2007).

https://doi.org/10.1021/ma071131o

[45] Khire V. S., Lee T. Y., Bowman C. N.: Surface modification using thiol-acrylate conjugate addition reactions. Macromolecules, 40, 5669-5677 (2007).

https://pubs.acs.org/doi/10.1021/ma070146j

[46] Yang W., Rånby B.: Photoinitiation performance of some ketones in the LDPE-acrylic acid surface photografting system. European Polymer Journal, 35, 1557-1568 (1999).

https://doi.org/10.1016/S0014-3057(98)00231-6

[47] Yang W., Rånby B.: Radical living graft polymerization on the surface of polymeric materials. Macromolecules, 29, 3308-3310 (1996). https://doi.org/10.1021/ma9515543

[48] Ma H., Davis R. H., Bowman C. N.: Principal factors affecting sequential photoinduced graft polymerization. Polymer, 42, 8333-8338 (2001). https://doi.org/10.1016/S0032-3861(01)00328-7

[49] Benetti E. M., Zapotoczny S., Vancso G. J.: Tunable thermoresponsive polymeric platforms on gold by 'photoiniferter'-based surface grafting. Advanced Materials, 19, 268-271 (2007).

https://doi.org/10.1002/adma.200601554

[50] Tazaki T., Otsu T.: Radical polymerization of methyl methacrylate with methyl 2,2-dimethyl-3,3-diphenyl3-cyanopropionate as a thermal iniferter. Polymer Bulletin, 17, 127-134 (1987).

https://doi.org/10.1007/BF00256877

[51] Heeb R., Bielecki R. M., Lee S., Spencer N. D.: Roomtemperature, aqueous-phase fabrication of poly (methacrylic acid) brushes by UV-LED-induced, controlled radical polymerization with high selectivity for surface-bound species. Macromolecules, 42, 9124-9132 (2009). https://doi.org/10.1021/ma901607w

[52] Li A., Benetti E. M., Tranchida D., Clasohm J. N., Schönherr H., Spencer N. D.: Surface-grafted, covalently cross-linked hydrogel brushes with tunable interfacial and bulk properties. Macromolecules, 44, 5344 5351 (2011).

https://pubs.acs.org/doi/10.1021/ma2006443
[53] Deng J-P., Yang W-T.: Self-initiating performance of maleic anhydride on surface photografting polymerization. Journal of Polymer Science Part A: Polymer Chemistry, 39, 3246-3249 (2001).

https://doi.org/10.1002/pola.1307

[54] Taniguchi M., Pieracci J., Samsonoff W. A., Belfort G.: UV-assisted graft polymerization of synthetic membranes: Mechanistic studies. Chemistry of Materials, 15, 3805-3812 (2003). https://doi.org/10.1021/cm020283p

[55] Rohr T., Ogletree D. F., Svec F., Fréchet J. M. J.: Surface functionalization of thermoplastic polymers for the fabrication of microfluidic devices by photoinitiated grafting. Advanced Functional Materials, 13, 264-270 (2003). https://doi.org/10.1002/adfm.200304229

[56] Gupta S., Agrawal M., Conrad M., Hutter N. A., Olk P., Simon F., Eng L. M., Stamm M., Jordan R.: Poly(2-(dimethylamino)ethyl methacrylate) brushes with incorporated nanoparticles as a SERS active sensing layer. Advanced Functional Materials, 20, 1756-1761 (2010). https://doi.org/10.1002/adfm.201000025

[57] Zhang N., Steenackers M., Luxenhofer R., Jordan R.: Bottle-brush brushes: Cylindrical molecular brushes of poly(2-oxazoline) on glassy carbon. Macromolecules, 42, 5345-5351 (2009).

https://doi.org/10.1021/ma900329y

[58] Steenackers M., Sharp I. D., Larsson K., Hutter N. A., Stutzmann M., Jordan R.: Structured polymer brushes on silicon carbide. Chemistry of Materials, 22, 272-278 (2009).

https://doi.org/10.1021/cm903051j

[59] Steenackers M., Gigler A. M., Zhang N., Deubel F., Seifert M., Hess L. H., Lim C. H. Y. X., Loh K. P., Garrido J. A., Jordan R., Stutzmann M., Sharp I. D.: Polymer brushes on graphene. Journal of the American Chemical Society, 133, 10490-10498 (2011). https://doi.org/10.1021/ja201052q

[60] Shiojima T., Inoue Y., Kyomoto M., Ishihara K.: Highefficiency preparation of poly(2-methacryloyloxyethyl phosphorylcholine) grafting layer on poly(ether ether ketone) by photoinduced and self-initiated graft polymerization in an aqueous solution in the presence of inorganic salt additives. Acta Biomateriala, 40, 38-45 (2016). https://doi.org/10.1016/j.actbio.2016.05.004

[61] Sheng W., Li W., Li B., Li C., Xu Y., Guo X., Zhou F., Jia X.: Mussel-inspired photografting on colloidal spheres: A generalized self-template route to stimuliresponsive hollow spheres for controlled pesticide release. Macromolecular Rapid Communications, 36, 1640-1645 (2015).

https://doi.org/10.1002/marc.201500239

[62] Bai G., Ma S., Qie R., Liu Z., Shi Y., Li C., Wang R., Guo X., Zhou F., Jia X.: UV-triggered surface-initiated polymerization from colorless green tea polyphenolcoated surfaces. Macromolecular Rapid Communications, 37, 1256-1261 (2016).

https://doi.org/10.1002/marc.201600065 